Multiple Classification Analyses on responses from 946 white women, drawn from the 1972 American National Election Study survey, were used to test the "frustrated homemaker hypothesis" that full-time homemakers are more dissatisfied with their lives than women employed outside the home. The fit bet ween actual and desired roles proved to be a better predictor of personal satisfaction than the traditional dichotomy between homemakers and employed women. Homemakers who had wanted a career were more personally dissatisfied than homemakers who had never wanted a career. The career-oriented homemakers were the ones who expressed greater personal dissat isfaction than employed women. Employed women and career-oriented homemakers were about equally critical of women's collective position in society, while homemakers who had never wanted a career were more accepting of women's status quo. The importance of including evaluations of both personal and collective wellbeing was shown by the fact that these two domains bore different relationships to employment-homemaker status.

\title{
Re-Examining the Frustrated Homemaker Hypothesis
}

\author{
ROLE FIT, PERSONAL DISSATISFACTION, \\ AND COLLECTIVE DISCONTENT
}

\author{
ALOEN TOWNSEND \\ PATRICIA GURIN \\ University of Michigan
}

ver the past two decades there has been a dramatic increase in the number of American women employed outside the home. A recent report by The Urban Institute (Smith, 1979) predicts that full-time homemaking will charac-

\footnotetext{
Authors' Note: The research reported here was supported by the National Institute of Mental Health, under research grant 5 ROIMH30920 02. Funds for computer support were provided by the Department of Psychology, University of Michigan.
}

SOCIOLOGY OF WORK AND OCCUPATIONS, Vol. 8 No. 4, November $1981464-488$ (C) 1981 Sage Publications, Inc. 
terize only one-quarter of married women in the United States by 1990 . This large-scale movement of women into the paid labor force has led to increased interest in the relationship between employment status and perceived well-being for women.

In particular, the past twenty years have shifted discussion from the joys and satisfactions of full-time homemaking to the psychological frustrations and social costs of restricting women's opportunities outside the home. The publication of Betty Friedan's (1963) book, The Feminine Mystique, jolted the 1950s image of the happy homemaker. Jessie Barnard (1972: 52) went so far as to warn, in The Future of Marriage, that "the housewife syndrome might well be viewed as Public Health Problem Number One." Empirical evidence for greater dissatisfaction among full-time homemakers than among women employed outside the home - the frustrated homemaker hypothesis - is slim, however. Ferree (1976) concluded that full-time homemakers were more likely to be dissatisfied with the way they were spending their lives, to feel they had not had fair opportunities in life, and to want their daughters to be "mostly different" from themselves. Ferree attributed these results to greater meaninglessness, powerlessness, and social isolation associated with full-time housework.

Ferree's conclusion that homemakers are more dissatisfied than employed women has been challenged by Wright (1978). His analysis of measures of happiness and life satisfaction from six national surveys indicated that differences in satisfaction between homemakers and employed women were generally small, not statistically significant, and evident on only a few items. He concluded that both full-time homemaking and paid employment have costs and benefits attached to them and that, on balance, both groups of women are equally satisfied with their lives. Our overall perspective on the relationship between employment status and women's perceptions of well-being has been circumscribed in several important ways, making it difficult to evaluate the validity of the frustrated homemaker hypothesis, however. 
First, conclusions generally have been based on restricted samples-for example, only working-class women (Ferree, 1976), middle-class women (Lopata, 1971), married women (Iglehart, 1979), or employed mothers (Nye and Hoffman, 1963). While such analyses give us a deeper understanding of the lives of certain groups of women, in-depth research has typically been bought at the price of small, possibly unrepresentative, local samples. The paucity of large-scale national data relevant to this issue limits our ability to assess the relative impact of demographic variables, across the full range of women's life conditions.

The Quality of American Life survey, conducted in 1971 (Campbell et al., 1976), and the nineteen-year replication of the Americans View Their Mental Health study, conducted in 1976 by Veroff et al. (1981), are two notable exceptions to this criticism. The latter data are especially interesting for the crosstime perspective they afford. Veroff et al. conclude that the job role has become much more salient to women across this nineteen-year span. The importance of including a broad demographic spectrum, in order to understand women's wellbeing, is underscored by their conclusion that sex, age, and education exert powerful influences on people's subjective well-being. For example, the relative happiness of homemakers and employed women shifts across different age groups: Among women aged 21 to 34 and 35 to 54 in 1976, full-time homemakers are slightly less likely than employed women to evaluate their present lives as "not too happy," while among women over 54 the trend is the reverse. After controlling for age, education, and year the survey was conducted, however, on most measures of well-being Veroff et al. (1981: 45) found "little to indicate that being employed vs. being a housewife meant something different and better for women's subjective mental health in 1976 compared to 1957."

Campbell et al. (1976) similarly concluded that general life satisfaction varied little between full-time homemakers and employed women. They, too, highlighted the importance of factors other than employment status in explicating women's 
sense of well-being. For example, they found that single employed women and homemakers who were college graduates were more likely to report dissatisfaction with their lives than women who were married or who had less than a college degree. Like Veroff et al. (1981), Campbell et al. (1976) concluded that, while employment is an increasingly important component of many women's lives, demographic characteristics-age, education, and family life cycle - must be taken into account in any analysis of perceived well-being.

Our second criticism of earlier research is that it has made categorical comparisons between employed women and homemakers. While these categorical distinctions are useful in illuminating the impact of objective differences in work status, they have deterred us from closer scrutiny of subjective differences within each group that may affect well-being. Specifically, such global descriptions neglect the question of role fit, a factor that we believe is a crucial mediator of subjective well-being. By the term "role fit" we mean the congruence or discrepancy between a woman's objective situation and her preferred or ideal situation. Campbell et al. (1976) clearly indicated the importance of such aspirations in either enhancing or muting satisfaction, although, unfortunately, their study only assessed aspirations regarding the residential environment. At least with regard to satisfaction with one's housing and neighborhood, though, the difference between respondents' ratings of their ideal circumstances and their current situations was highly correlated with satisfaction (Campbell et al., 1976: Ch. 6).

With regard specifically to women's aspirations, several studies indicate that a decreasing proportion of American women prefer full-time homemaking to combining family and paid employment in some way. For example, comparing attitudes of female college students in 1969 and 1973, Parelius (1975) found increases in both the percentage of women intending to combine marriage, family, and a career ( $56 \%$ of 
147 women in 1969 and $63 \%$ of 200 women in 1973) and the percentage intending to continue working all their adult lives (16\% in 1969 and 37\% in 1973). Between 1957 and 1976, Iglehart (1979) found a decrease from $22 \%$ to $3 \%$ in the percentage of white, married, employed women who said they would prefer full-time homemaking to being employed. Among full-time homemakers she found an increase in the percentage who felt neutral or ambivalent about housework $(27 \%$ in 1957 to $44 \%$ in 1976), as well as an increase in the percentage who planned to work in the future $17 \%$ of the homemakers in 1957 and $37 \%$ in 1976). This evidence indicates that the proportion of women preferring to devote themselves exclusively to homemaking has decreased in recent years and no longer constitutes the majority position.

Only one study, however, has explicitly examined the frustrations and satisfactions of homemakers who do and do not want to be employed. Fidell (n.d.) found that $29 \%$ of a sample of 465 mostly married, middle- and working-class women were full-time homemakers who did not want to be employed. Most important for our argument, these homemakers who did not want to be employed reported better physical and mental health, happier marriages, and greater feelings of control over their lives than either homemakers who wanted to be employed ( $18 \%$ of the sample) or women who were employed $(53 \%)$. It was the homemakers who wanted to be employed who looked worst off on these indicators of the frustrated homemaker syndrome. Clearly, Fidell's evidence is that homemakers desiring a role outside the home are expressing dissatisfaction and frustration with their lives, while, for women who do not desire a role outside the home, homemaking is providing a satisfying and gratifying lifestyle.

Our third criticism of previous research on perceived wellbeing is that it has been largely concerned with satisfaction with one's own personal life, phrased in highly individualistic terms. As epitomized by the women's movement slogan, "the 
personal is political," assessment of any individual woman's circumstances may be linked to perceptions of the options offered to women as a group in our society. Runciman (1966), in his study of class consciousness, demonstrated a similar distinction between "egoist deprivation"-comparing oneself to other individuals - and "fraternalist deprivation"-comparing one's reference group to some other group or groups. Although it has been implied in some discussions of the women's movement that discontent with women's traditional roles stems largely from individual deprivation or personal grievances, the only empirical study testing this hypothesis (Crosby, 1978), found no such relationship. Thus, the extent to which dissatisfaction with one's own life may be linked to dissatisfaction with women's roles in society remains an open empirical question.

Our research was intended to address these three criticisms in the following ways. First, our data come from a large nationally representative survey, allowing us to include a wide range of demographic groups and to look at employed women and homemakers simultaneously. Second, we incorporated the concept of role fit into our analysis by dividing the homemakers into two groups: those who never wanted a career and those who did. Unfortunately, there were no questions in the survey that would allow us to make a similar distinction among employed women, between those who preferred employment and those who would rather have stayed at home. Thus, our role fit variable applies only to the homemakers.

Third, our research distinguishes between personal and collective discontent. The measures of personal dissatisfaction ask respondents to judge their own life circumstances, while the measures of collective discontent tap their evaluations of the position of women as a group in our society. This permits empirical investigation of the independence or linkage between these two types of assessments and their relationship to homemakers' role fit and to employment status. 


\section{HYPOTHESES}

The fit between one's actual and desired roles should be a better predictor of personal satisfaction than the traditional dichotomy between employment and homemaker status. Specifically, we predicted that role fit mutes dissatisfaction: Homemakers who had never wanted a career were expected to be less satisfied with their personal lives than career-oriented homemakers.

In addition, in line with previous research identifying frustrated homemakers, we expected those career-oriented homemakers to be more dissatisfied than employed women with their personal lives. While employment carries its own potential sources of dissatisfaction for women-for example, segregation in lower-status jobs, limited opportunities for advancement, lower pay than men, the burden of juggling job and family responsibilities - it nonetheless provides women, like men, considerable gratification, certainly more than achieved by homemakers who have not managed to translate their career aspirations into actual employment. Thus, we expected that career-oriented homemakers would be more dissatisfied than either the employed women or their homemaker counterparts whose roles fit their aspirations. The latter two groups were not expected to differ much in their levels of personal life satisfaction, although the sources of that satisfaction might vary greatly among employed women and home-oriented homemakers.

Role discrepancy, we felt, would not work in the same cumulative way to make the career-oriented homemakers the most dissatisfied on the measures of collective discontent, however. In fact, most research on this topic has found that negative evaluation of women's place in society, particularly of traditional roles for women, is greater among employed women than among full-time homemakers (Blanchard et al., 1976; Mason et al., 1976; Thornton and Freedman, 1979). 
Suggested explanations include personal experience with sex discrimination in the job market, exposure to egalitarian ideologies and to diverse role models, and changes in attitudes to conform to new behaviors through the employment experience.' We thus expected that collective discontent would be greater among employed women than in either group of fulltime homemakers.

Within the homemaker category, we speculated that the career-oriented homemakers would be subject to conflicting pressures. While their desire for a role outside the home was expected to contribute to greater criticism of women's place in society, we thought that their actual status as homemakers would have indicated some acceptance of traditional roles. Moreover, however much they may have wanted careers, they had not had the "consciousness-raising" experiences that employment has been suggested to provide. Therefore, we hypothesized that the level of collective discontent among career-oriented homemakers would be somewhat lower than that of employed women, yet greater than among homeoriented homemakers.

In brief, we predicted that the career-oriented homemakers would show the highest levels of personal discontent, while the employed women would show the highest levels of collective discontent.

\section{METHOD}

\section{SAMPLE}

The data come from the 1972 American National Election Study, conducted by the Center for Political Studies of the Institute for Social Research at The University of Michigan. The 2705 men and women interviewed in this survey were a representative cross-section of U.S. citizens, age 18 and older, living in private households in the coterminous United States. Our analyses focus on white women who, at the time of the 
interview, either were employed outside the home or were fulltime homemakers. ${ }^{2}$

\section{OPERATIONALIZATION OF ROLE FIT}

Role fit was operationalized by dividing the homemakers into two groups: those who said "yes" to the question, "Have you ever wanted a career?"- the career-oriented homemakers (role discrepancy) - and those who said "no," they had never wanted a career-the home-oriented homemakers (role fit). ${ }^{3}$ No definition of what constitutes a "career" was provided, so our classification must acknowledge possible subjective differences in interpretation of the question. It is also important to note that this question assesses respondents' current perceptions of their career orientation, even though it asks about the past. There is simply no way to know how accurate their recollections are.

\section{MEASURES OF PERSONAL DISSATISFACTION}

Three questions measuring personal dissatisfaction were included. ${ }^{4}$

Dissatisfaction with Life. Dissatisfaction with one's life was measured by asking, "In general, how satisfying do you find your life these days? Would you call it completely satisfying, pretty satisfying, or not very satisfying?" Responses were scored 1 for "completely or pretty satisfying" and 2 for "not very satisfying."

Sense of Restriction. Sense of restricted opportunities was measured by the question, "Do you think you have had a fair opportunity to make the most of yourself in life, or have you been held back in some ways?" Responses were scored 1 for "fair opportunities" and 2 for "held back." 
Sense of Unfulfillment. Sense of unfulfilled ambitions was measured by the question, "Up to now, have you been able to satisfy most of your ambitions in life or have you had to settle for less than you had hoped for?" Responses were scored 1 for "able to satisfy ambitions" or (volunteered) "still working on it," and 2 for "settled for less."

\section{MEASURES OF COLLECTIVE DISCONTENT}

Four measures evaluating discontent with women's position in society were included. 5

Power Discontent. Evaluation of the amount of influence women have as a group "in American life and politics" was measured by asking respondents to choose one of three alternatives: too much influence, just the right amount, or too little influence. Responses were scored 1 for "too much influence" or "about right," and 2 for "too little influence."

Perceived Discrimination. Awareness of sex discrimination was measured by asking respondents to indicate strength of agreement or disagreement with the statement, "Our society discriminates against women." Responses were scored 1 for "disagree strongly" or "somewhat" and 2 for "agree strongly" or "somewhat."

System Blame Index. An index of four sets of forced-choice items was used to measure respondents' beliefs about the causes of status differentials between men and women. In each set of items, one statement attributes sex differentials to inequities in the social system, while the other statement attributes these differentials to women's personal deficiencies. Responses on the index were collapsed at the median so that a score of 1 represents blame on women and 2 represents blame on the system. 
Equal Role Orientation. Belief about appropriate roles for women and men was measured by asking respondents to place themselves along a 7-point scale (from 1, representing "equal role," to 7, representing "at home") for the following statement: "Recently there has been a lot of talk about women's rights. Some people feel that women should have an equal role with men in running business, industry, and government. Others feel that women's place is in the home. Where would you place yourself on this scale, or haven't you thought much about this?" Categories 4-7 were collapsed and scored 1 for traditional role orientation, and categories 1-3 were scored 2 for equal role orientation.

\section{RESULTS}

The sample of 946 white women was split, $45 \%$ employed ( $N$ $=429)$ and $55 \%$ full-time homemakers $(\mathrm{N}=517)$. When the homemakers were divided according to the role fit variable, $17 \%$ of the sample $(30 \%$ of the homemakers) were careeroriented homemakers and $38 \%$ ( $70 \%$ of the homemakers) were home-oriented homemakers.

Because age, education, and marital status have been shown to be important predictors of life satisfaction (Campbell et al., 1976; Veroff et al., 1981) and of nontraditional sex role attitudes (Mason et al., 1976: Thornton and Freedman, 1979), we compared the employed women, home-oriented homemakers, and career-oriented homemakers on these demographic characteristics. ${ }^{6}$ The results are shown in Table 1. Home-oriented homemakers are significantly older, less well educated, and more likely to be widowed, while the employed group is notable for its larger percentage of never-married, divorced, and separated women. Because of these demographic differences between groups, age, education, and marital status are controlled in the analyses of role fit. ${ }^{7}$ 


\section{TABLE 1}

Age, Education, and Marital Status of Employed Women, Career-Oriented Homemakers, and Home-Oriented Homemakers

\begin{tabular}{|c|c|c|c|}
\hline & $\frac{\text { Employed }}{(429)}$ & $\begin{array}{l}\text { Career- } \\
\text { Oriented } \\
\frac{\text { Homemakers }}{(157)}\end{array}$ & $\begin{array}{l}\text { Home- } \\
\text { Oriented } \\
\frac{\text { Homemakers }}{(360)}\end{array}$ \\
\hline \multicolumn{4}{|l|}{ Age } \\
\hline $18-29$ & $31 \%$ & $36 \%$ & $16 \%$ \\
\hline $30-49$ & 40 & 28 & 34 \\
\hline \multirow[t]{2}{*}{50 and older } & $\frac{29}{100 \%}$ & $\frac{36}{100 \%}$ & $\frac{50}{100 \%}$ \\
\hline & \multicolumn{3}{|c|}{$x^{2}=51.59, d f=4, p<.001$} \\
\hline \multicolumn{4}{|l|}{ Education } \\
\hline $0-8$ grades & $7 \%$ & $11 \%$ & $30 \%$ \\
\hline $9-12$ grades & 58 & 57 & 57 \\
\hline \multirow[t]{2}{*}{ more than 12} & $\frac{35}{100 \%}$ & $\frac{32}{100 \%}$ & $\frac{13}{100 \%}$ \\
\hline & \multicolumn{3}{|c|}{$x^{2}=105.01, d f=4, p<.001$} \\
\hline \multicolumn{4}{|l|}{ Marital Status } \\
\hline Larried & $61 \%$ & $82 \%$ & $74 \%$ \\
\hline Sing $1 e^{a}$ & 28 & 4 & 4 \\
\hline \multirow[t]{2}{*}{ Widowed } & $\frac{11}{100 \%}$ & $\frac{14}{100 \%}$ & $\frac{22}{100 \%}$ \\
\hline & \multicolumn{3}{|c|}{$x^{2}=110.44, d f=4, p<.001$} \\
\hline
\end{tabular}

a. Includes never married, divorced, and separated.

Confirmation that personal dissatisfaction and collective discontent are independent domains of well-being is provided by results of factor analyzing the seven dependent variables. ${ }^{8}$ The first factor shown in Table 2 includes all four of the collective discontent measures, while the second is composed of the three personal dissatisfaction measures. The separation could not be more dramatic.

To test the hypothesis that role fit would be a better predictor than the employment dichotomy, Multiple Classification Analyses (MCAs) were run on each of the dependent 


\section{TABLE 2}

Varimax Rotated Factor Loadings of Personal Dissatisfaction and Collective Discontent Measures

\begin{tabular}{|c|c|c|}
\hline \multirow[b]{2}{*}{ Measure } & Factor & Factor \\
\hline & 1. & 2 \\
\hline Dissatisfaction With Life & .06 & .41 \\
\hline Sense of Restriction & .05 & .51 \\
\hline Sense of Unfulfillment & .04 & .55 \\
\hline Power Discontent & .47 & .01 \\
\hline Perceived Discrimination & -.50 & -.07 \\
\hline System Blame & .66 & .12 \\
\hline Equal Role Orientation & -.54 & -.04 \\
\hline Eigenvalues & 1.29 & 0.67 \\
\hline \multicolumn{3}{|l|}{ Percentage of Common } \\
\hline Variance Explained & 61.7 & 38.3 \\
\hline \multicolumn{3}{|l|}{ Percentage of Total } \\
\hline Variance Explained & 17.3 & 10.7 \\
\hline
\end{tabular}

variables, using as predictors age, education, marital status, and the simple dichotomy of employed versus homemaker groups. ${ }^{9}$ Then the MCAs were repeated, using the three groups in the role fit variable: employed women, career-oriented homemakers, and home-oriented homemakers. While very little variance in the personal dissatisfaction measures is explained by either set of predictors, slightly more is explained when role fit (adjusted multiple $\mathrm{R}^{2}=.05$ across all three measures) rather than simple employment status (adjusted multiple $\mathrm{R}^{2}=.03, .01$, and .03 , respectively) is included in the predictor set. 
TABLE 3

Summary of MCAs on Three Measures of Personal Dissatisfaction

\begin{tabular}{|c|c|c|c|c|c|c|c|}
\hline \multirow{2}{*}{$\begin{array}{l}\text { PREDICTORS } \\
\text { Role Fit }\end{array}$} & \multirow[t]{2}{*}{$\underline{\mathbf{N}}$} & \multicolumn{2}{|c|}{$\begin{array}{l}\text { DISSATISFACTION } \\
\text { WTH LIFE }\end{array}$} & \multicolumn{2}{|c|}{$\begin{array}{r}\text { SENSE OF } \\
\text { RESTRICT ION } \\
\end{array}$} & \multicolumn{2}{|c|}{$\begin{array}{c}\text { SENSE OF } \\
\text { LNFULFILLMENT }^{c}\end{array}$} \\
\hline & & $\begin{array}{l}\text { Unadjusted } \\
\text { Mean }\end{array}$ & $\begin{array}{l}\text { Adjusted } \\
\text { Meand } \\
\end{array}$ & $\begin{array}{l}\text { Unadjusted } \\
\text { Mean } \\
\end{array}$ & $\begin{array}{l}\text { Adjusted } \\
\text { Meand } \\
\end{array}$ & $\begin{array}{c}\text { Unadjusted } \\
\text { Mean } \\
\end{array}$ & $\begin{array}{l}\text { Ad jusced } \\
\text { Meand } \\
\end{array}$ \\
\hline $\begin{array}{l}\text { Employed } \\
\text { Career-oriented }\end{array}$ & 428 & 1.10 & 1.10 & 1.25 & 1.25 & 1.33 & 1.33 \\
\hline Homemakers & 156 & 1.16 & 1.18 & 1.44 & 1.46 & 1.43 & 1.47 \\
\hline $\begin{array}{l}\text { Home-orlented } \\
\text { Homemakers }\end{array}$ & 354 & 1.06 & 1.06 & 1.22 & 1.20 & 1.26 & 1.25 \\
\hline $\mathrm{E}^{2}$ or $\mathrm{B}^{2^{\mathrm{e}}}$ & & .01 & $.02^{\star \star}$ & .03 & $.04^{* \star}$ & .01 & $.03^{\star \star}$ \\
\hline \multicolumn{8}{|l|}{ Marital Status } \\
\hline $\begin{array}{l}\text { Married } \\
\text { Singlef } \\
\text { Widowed }\end{array}$ & $\begin{array}{l}654 \\
138 \\
146\end{array}$ & $\begin{array}{l}1.06 \\
1.18 \\
1.18\end{array}$ & $\begin{array}{l}1.06 \\
1.19 \\
1.17\end{array}$ & $\begin{array}{l}1.25 \\
1.34 \\
1.29\end{array}$ & $\begin{array}{l}1.25 \\
1.37 \\
1.26\end{array}$ & $\begin{array}{l}1.27 \\
1.46 \\
1.41\end{array}$ & $\begin{array}{l}1.28 \\
1.48 \\
1.37\end{array}$ \\
\hline$E^{2} \circ B^{2}$ & & .03 & $.04^{\star \star}$ & .00 & $.01 *$ & .02 & $.03^{\star \star}$ \\
\hline \multicolumn{8}{|l|}{ Education } \\
\hline $\begin{array}{l}0-8 \text { grades } \\
9-12 \text { grades } \\
\text { more chan } 12\end{array}$ & $\begin{array}{l}152 \\
538 \\
248\end{array}$ & $\begin{array}{l}1.14 \\
1.10 \\
1.07\end{array}$ & $\begin{array}{l}1.14 \\
1.11 \\
1.06\end{array}$ & $\begin{array}{l}1.38 \\
1.27 \\
1.22\end{array}$ & $\begin{array}{l}1.41 \\
1.27 \\
1.19\end{array}$ & $\begin{array}{l}1.38 \\
1.33 \\
1.26\end{array}$ & $\begin{array}{l}1.37 \\
1.34 \\
1.24\end{array}$ \\
\hline$E^{2}$ or $B^{2}$ & & .00 & $.01^{\star}$ & .01 & $.02^{\star \star}$ & .01 & $.01^{\star}$ \\
\hline \multicolumn{8}{|l|}{ Age } \\
\hline $\begin{array}{l}18-29 \\
30-49 \\
50 \text { and older }\end{array}$ & $\begin{array}{l}247 \\
337 \\
354\end{array}$ & $\begin{array}{l}1.08 \\
1.09 \\
1.12\end{array}$ & $\begin{array}{l}1.09 \\
1.11 \\
1.10\end{array}$ & $\begin{array}{l}1.28 \\
1.24 \\
1.30\end{array}$ & $\begin{array}{l}1.27 \\
1.27 \\
1.28\end{array}$ & $\begin{array}{l}1.28 \\
1.29 \\
1.38\end{array}$ & $\begin{array}{l}1.27 \\
1.31 \\
1.36\end{array}$ \\
\hline $\mathrm{E}^{2}$ or $\mathrm{B}^{2}$ & & .00 & .00 & .00 & .00 & .01 & .01 \\
\hline Grand mean & & & 1.10 & & 1.27 & & 1.32 \\
\hline $\begin{array}{l}\text { Unadjusted } R^{2} \\
\text { Adjusted mu1tiple }\end{array}$ & $R^{2}$ & & $.05^{\star *}$ & & 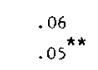 & & $.05^{\star \star}$ \\
\hline
\end{tabular}

a. Scored 1 = completely or pretty satisfying, 2 = not very satisfying.

b. Scored 1 = fair opportunities, 2 = held back.

c. Scored $1=$ able to satisfy ambitions, 2 = settled for less.

d. The adjusted means were obtained separately for each dependent variable from an MCA equation including all of the predictor variables listed above.

e. The $E^{2}$ figure is noted in the "unadjusted" column and the $B^{2}$ is noted in the "adjusted" column. Alpha levels indicate a predictor's marginal importance.

f. Inciudes never married, divorced, and separated.

$\star p=.01 ; * \star p=.001$

The results of the role fit analyses for the three personal dissatisfaction measures are shown in Table 3.10 The adjusted means for the role fit variable show that on each of the three personal measures it is the career-oriented homemakers who are most dissatisfied, even after controlling for demographic differences among the groups." This result is even clearer in the graph of these means presented in Figure 1.

The two measures directly assessing restricted opportunities or unfulfilled expectations clearly tap greater personal dissatis- 


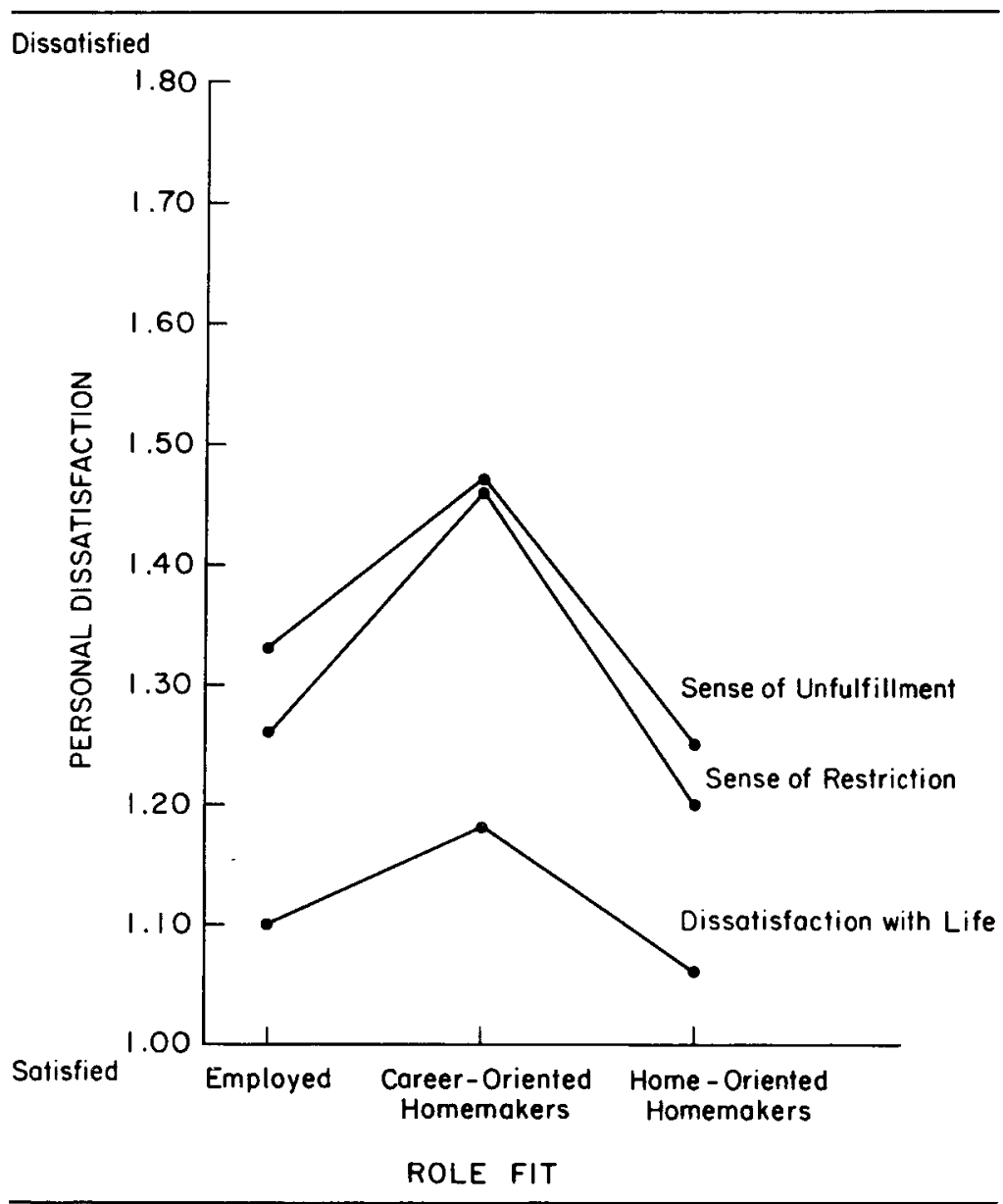

Figure 1: Adjusted Means on Three Measures of Personal Dissatisfaction for the Three Groups of Women

faction than the global evaluation of one's current life. Figure 1 makes clear, however, that we are talking about relative dissatisfaction in the career-oriented homemakers, since all three groups fall closer to the satisfied than the dissatisfied end of this continuum.

Table 3 also shows the importance of role fit relative to marital status, education, and age in accounting for personal 
life dissatisfaction. Overall, marital status and role fit explain somewhat more variance than either age or education. ${ }^{12}$ Marital status is more important than role fit in explaining the global measure of how satisfying women find their lives. The two variables are equally important in accounting for assessment of unfulfilled ambitions. And role fit exceeds marital status in explaining the sense of restriction. Thus, the one personal dissatisfaction measure that most specifically taps role frustration, being held back in life, is particularly well explained by the role fit variable.

The analysis of the four measures of collective discontent are shown in Table 4 and presented graphically in Figure $2 .{ }^{13}$ As predicted, the career-oriented homemakers are no longer the most dissatisfied group. Instead, they and the employed women closely resemble each other, and it is the home-oriented homemakers who stand out for their greater satisfaction with women's traditionally subordinate position in our society. Thus, contrary to our prediction, employment status itself is not the critical determinant of collective discontent. Rather, the orientation toward work outside the home that is shared both by the employed women and the career-oriented homemakers appears to be the important issue in women's appraisal of the collective condition of women. Table 4 also shows that role fit explains slightly more variance in women's evaluation of appropriate roles for women and men than in their perceptions of discrimination, causal attributions of sex differentials in job status or wages, and evaluations of women's influence in American life and politics.

The importance of role fit relative to education, marital status, and age depends on the particular measure of collective discontent. Role fit and education are the better predictors of equal role orientation and perceived discrimination. Role fit and age are the better predictors of women's discontent with women's influence in American life and politics. Also, role fit is less important than either age or education in explaining women's systemic attributions for sex disparities in job status and income. 


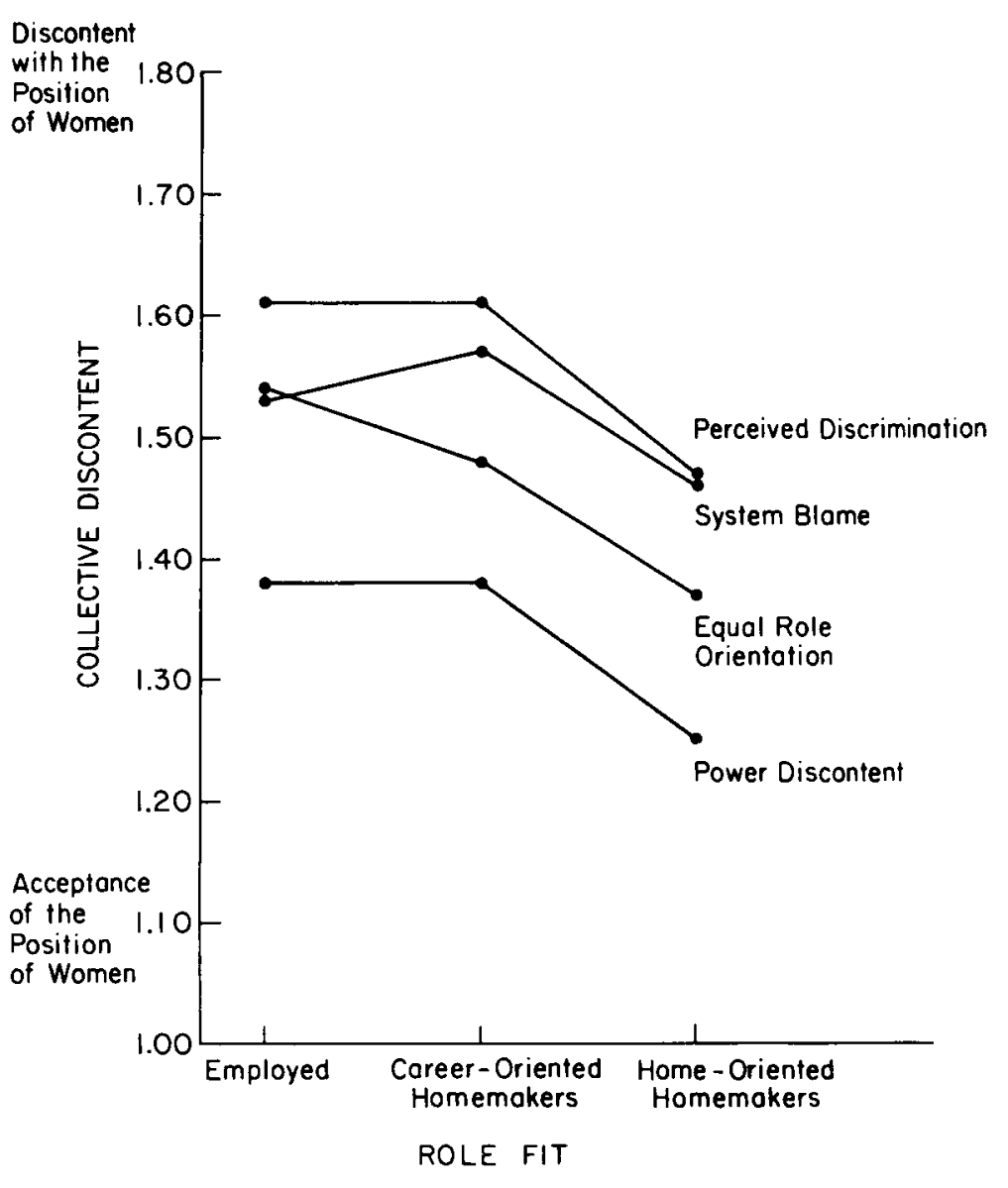

Figure 2: Adjusted Means on Four Measures of Collective Discontent for the Three Groups of Womell

The adjusted means of Table 4 indicate greater discontent with women's position among women under 30 and women with more than high school education, as well as among both the employed and the career-oriented homemakers. Thus, age, which was not related to personal dissatisfaction, is negatively related to collective discontent. Moreover, whereas a college education was associated with greater satisfaction with one's personal life, it is associated with greater dissatisfaction with 


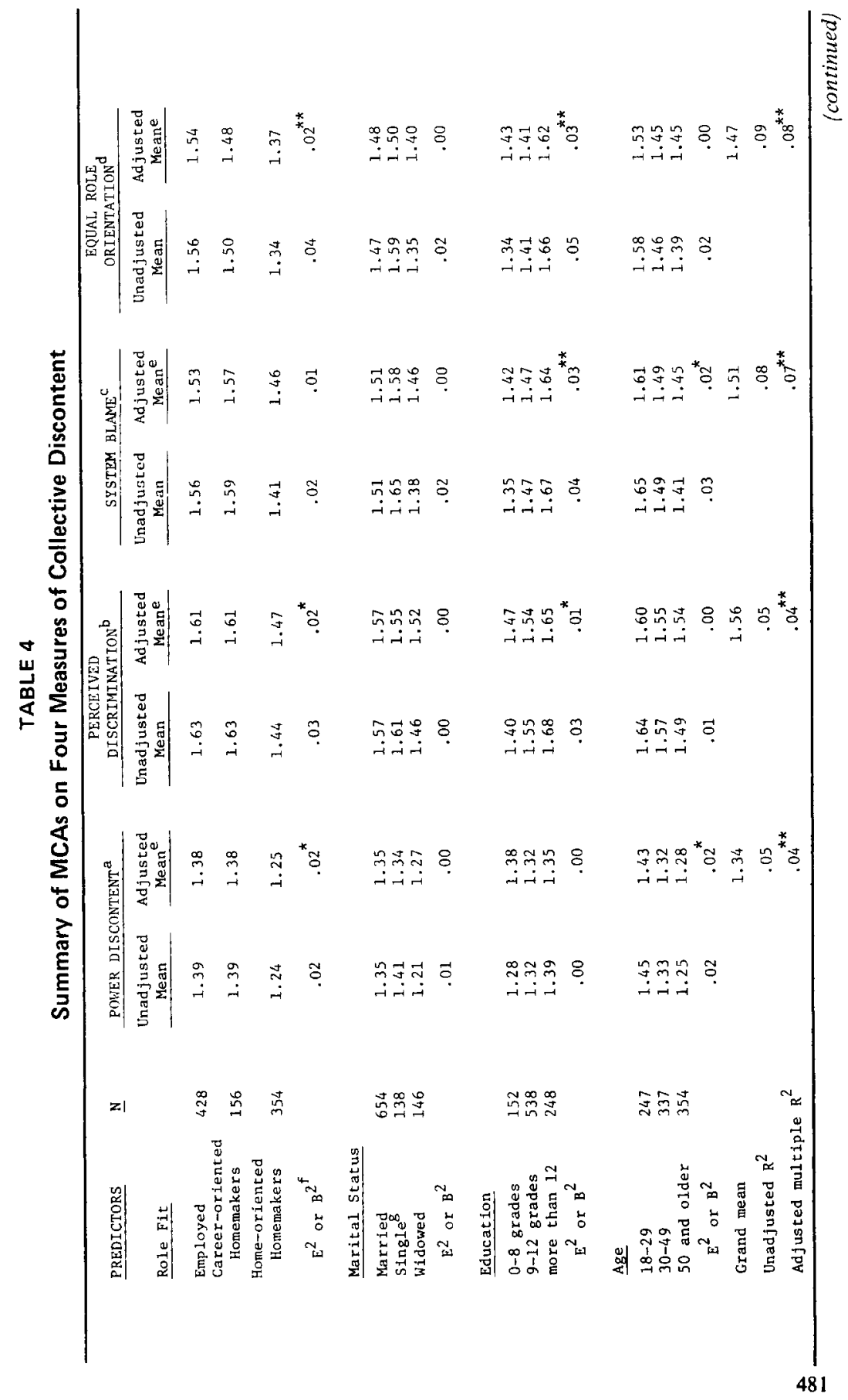




\section{NOTES FOR TABLE 4:}

a. Scored $1=$ too much influence or about right, 2 = too little influence.

b. Scored 1 = disagree strongly or somewhat, 2 = agree strongly or somewhat.

c. Scored 1 = blame women, 2 = blame the system.

d. Scored $1=$ not equal role, $2 \simeq$ equal role.

e. The adjusted means were obtained separately for each dependent variable from an MCA equation including all of the predictor variables listed above.

$f$. The $E^{2}$ figure is noted in the "unadjusted" column and the $B^{2}$ is noted in the

"adjusted" column. Alpha levels indicate a predictor's marginal importance.

g. Includes never married, divorced, and separated.

$\star p=.01 ; * \star p=.001$

women's place in society. It also explains more variance in women's collective discontent than in personal dissatisfactions. On two measures of collective discontent-system blame and equal role orientation-education is the most important predictor, while on a third-perceived discrimination-it is only slightly less important than role fit. Finally, marital status bears only a weak relationship to collective discontent, unlike its importance for personal dissatisfaction.

\section{CONCLUSIONS}

We conclude from these analyses that by incorporating the concept of role fit one can find women who typify either the image of the happy homemaker or the image of the frustrated homemaker. It makes little sense, therefore, to talk about the perceived well-being of homemakers as a global category.

Consistent with our hypothesis that role fit mediates personal satisfaction, we found that women who had wanted a career outside the home were more dissatisfied with their own lives than homemakers who had never wanted a career. It was just the career-oriented homemakers who showed the dissatisfaction previous research has suggested characterizes homemakers as opposed to employed women. The home-oriented homemakers, on the other hand, were slightly more satisfied with their lives than were employed women. 
Despite perceiving their opportunities as more restricted, the career-oriented homemakers nonetheless were fairly satisfied with their lives. The extent to which personal dissatisfaction was expressed by the three groups of women depended partly on the question asked. The two measures that tapped sense of constraint differentiated between the groups more clearly than the global measure did. This result is consistent with Campbell et al.'s (1976) finding that global measures of life satisfaction seem less useful if one's goal is to assess sources of dissatisfaction.

The analyses of collective discontent showed about equal criticism among employed women and career-oriented homemakers, while home-oriented homemakers were more accepting of women's current position. Thus, contrary to some popular depictions of the women's movement as lacking support among homemakers, there are clearly some women in the home who share the concerns of employed women about discrimination and restricted power. Paid employment, whether a present or a desired status, appears to be a critical factor associated with collective discontent among women.

These results highlight the importance of including perceptions of both personal and collective deprivation in research on women's well-being. The personal and collective domains are independent. Women who criticize the collective condition of women are not necessarily less satisfied with their own lives. Moreover, personal and collective evaluations do not bear the same relationships to employment-homemaker status. Thus, while employed women on the average were satisfied with their own lives, they were much less satisfied with women's collective power and status. Career-oriented homemakers, on the other hand, were dissatisfied with both domains. The conditions under which dissatisfaction with one's own life becomes politicized into greater discontent with the opportunities available to a whole stratum and systemic barriers become apparent despite relative personal privilege are important arenas for further research. 
Although we have shown that role fit mediates perceptions of both personal and collective well-being among homemakers, further research is also needed to clarify why some women, regardless of employment status, feel their opportunities are restricted when others do not. Our results, like those of other national surveys (Campbell et al., 1976; Veroff et al., 1981), suggest that demographic characteristics such as marital status and education will be important factors to include in research on this issue.

Because the homemakers who had never wanted a career were older, less well educated, and more apt to be widowed, our results also raise questions about the relation of life satisfaction to social change and the meaning of role fit. Crosssectional analyses and panel data will be necessary to understand the extent to which full-time homemaking as a source of satisfaction is tied not to particular demographic subgroups, but to either a passing generation of our grandmothers or to a passing era.

\section{NOTES}

1. However, data suitable for evaluating the causal direction between nontraditional sex role attitudes and employment are largely unavailable. See Molm (1978) regarding this point.

2. This categorization was based on the respondents' employment status at the time of the postelection interview. Of these employed women, $93 \%$ had been employed or looking for work in the preelection interview. Our employment category makes no distinction between full and part-time work.

Of the homemakers, $89 \%$ had been full-time homemakers at the preelection interview, while $5 \%$ had previously been employed or looking for work. The homemaker category included 11 women $(2 \%)$ who said they were currently working less than 20 hours per week.

In nearly all of the previous research on women's well-being, women of color have either been excluded entirely or have represented a very small percentage of the samples. The 1972 ANES fits the latter case. For our purposes, it included 58 black women employed at the time of the interview, 13 black women who were classified as career-oriented homemakers, and 19 black women who were classified as home- 
oriented homemakers. Women of other minorities were excluded, since they represent less than $1 \%$ of the total ANES sample.

These small cell frequencies make detailed analysis of the black sample very tenuous. However, when we looked at results separately by race of the respondent, we found different patterns for black and white women: Role discrepancy was related to personal dissatisfaction for white women but not for black women. On the measures of collective discontent, simply being employed was a more important predictor among black women than the role fit effect evident in white women. We therefore decided to present just the results for white women in the tables until further research with larger numbers of black women can be done on the dynamics of their perceived well-being.

3. In addition, $\mathbf{3 8}$ homemakers said that they felt "mixed" about wanting a career. Preliminary analyses showed that these respondents tended to fall somewhere between the career-oriented homemakers and the home-oriented homemakers on the personal dissatisfaction measures. This, and the small cell size, led us to delete this group from the analyses presented here.

We were concerned that the question about having wanted a career might reflect a purely retrospective aspiration. This does not appear to be the case. Career-oriented homemakers were more likely to say they would take a job immediately if someone would take care of things at home $\left(X^{2}=48.51, \mathrm{df}=1, \mathrm{p}<.01\right)$. They were also more likely to think they actually would take a job in the future $\left(X^{2}=63.83, \mathrm{df}=1, \mathrm{p}<.01\right)$.

Finally, although we call the role-consistent women "home-oriented homemakers," we do not wish to imply that the career-oriented homemakers are any less committed to their homemaker role. Rather, we wanted to emphasize the fact that one group is expressing a desire for a role outside the home while the other is not.

4. Four other measures of personal dissatisfaction were available in the 1972 ANES survey. They are not included in the analyses because they were asked of only half the respondents.

5. The Power Discontent and System Blame Index measures were devised by Arthur Miller, Patricia Gurin, and Gerald Gurin of the Institute for Social Research at the University of Michigan. The dependent measures were dichotomized in order to fit the Multiple Classification Analysis requirement that the dependent variable be either dichotomized or an interval-level measure that is not badly skewed (see Andrews et al., 1973).

6. Income has also been studied as an important predictor of subjective wellbeing. Although cross-sectional data have shown greater life satisfaction to be associated with higher income (Campbell et al., 1976), Easterlin (1973) has argued that this relationship does not hold true when material well-being is measured as relative standing rather than absolute dollars.

The home-oriented homemakers were significantly less well off, in terms of family income, than the other two groups $\left(X^{2}=29.06, \mathrm{df}=4, \mathrm{p}<.01\right)$. However, we did not include income as a demographic control in the analyses presented here, because preliminary results indicated that income, at least in absolute terms, did not do as much to clarify the role fit concept as the other three demographic controls.

7. Education and age, not surprisingly, are significantly related to each other $(r=$ -.36 ), so that we could have used one rather than the other. However, while Campbell et al. (1976) found that life satisfaction generally increased with age, the role of education appears to be more problematic for women: Homemakers with college 
degrees in the Campbell et al. data exhibited much lower life satisfaction than did employed women with college degrees. We therefore decided to control simultaneously for all three demographic variables.

8. These factor analyses, as well as the rest of the data computation, were done using the OSIRIS computer software system, which was developed by the Institute for Social Research at the University of Michigan, through funding from the National Science Foundation, the Inter-University Consortium for Political Research, and other sources.

The OSIRIS factor analysis program uses a principal-axes algorithm to extract factors. Squared multiple correlations were chosen as communality estimates, Kaiser's criterion was employed to determine the number of factors for the solution, and an orthogonal (varimax) rotation was performed. For a more compete explanation of factor analysis, see Harman (1967).

9. Multiple Classification Analysis (MCA) is a form of dummy variable regression. As such, it is intended for use with an interval-level (or dichotomous) dependent variable and multiple categorical predictors. Unlike dummy variable regression, MCA does not exclude any of the predictor categories. Another advantage of MCA is that it does not assume that the additive effects of the predictors on the dependent variable are necessarily linear (see Andrews et al., 1973).

10. These three dependent variables appear to tap different, although moderately intercorrelated, domains of life satisfaction, as shown by the Pearson correlations below:

Dissatisfaction with life

Sense of restriction

Sense of unfulfillment

.27

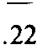

Life Restriction

$\begin{array}{ll}27 & 37\end{array}$

Because MCA treats all predictors as if they were categorical, the education and age controls were collapsed as shown in Table 3.

11. These means include adjustments for any peculiarities in the distribution of cases across all the other predictors in the analysis.

12. There are two ways of reaching this conclusion. First, the eta-square values indicate the bivariate zero-order correlation or the amount of variance explained in the dependent variable by each predictor, without adjusting for any overlap between predictors. Second, the beta-square values are the multivariate analogue of eta-square values and indicate the reduction in variation on the dependent variable that would occur if variation were measured around the adjusted means rather than the grand mean.

13. As with the personal dissatisfaction measures, our collective discontent measures are moderately intercorrelated, as shown in the Pearson correlations below:

Power Discrimination Blame

Power Discontent

Perceived Discrimination $\quad-.23$

System Blame Index $\quad .37$

Equal Role Orientation $\quad-.25$

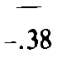

.30 


\section{REFERENCES}

ANDREWS, F., J. MORGAN, J. SONQUIST and L. KLEM (1973) Multiple Classification Analysis. Ann Arbor: Institute for Social Research, University of Michigan.

BERNARD, J. (1972) The Future of Marriage. New York: Bantam Books.

BLANCHARD, C., J. BECKER and A. BRISTOW (1976) "Attitudes of southern women: selected group comparisons." Psychology of Women Q. 1, 2: 160-171.

CAMPBELL, A., P. CONVERSE, W. RODGERS (1976) The Quality of American Life. New York: Russell Sage Foundation.

CROSBY, F. (1978) "Relative deprivation and working women: causes of their discontents." Presented at the first annual meeting of the International Society for Political Psychology, New York, September.

EASTERLIN, R. (1973) "Does money buy happiness?" The Public Interest 30: 3-10.

FERREE, M. (1976) "Working-class jobs: housework and paid work as sources of satisfaction." Social Problems 23: 431-441.

FIDELL, L. (n.d.) "Employment status, role dissatisfaction and the housewife syndrome." Unpublished manuscript. (Available from the author, Psychology Department, California State University, Northridge, California 91324.)

FRIEDAN, B. (1963) The Feminine Mystique. New York: Norton.

HARMAN, H. (1967) Modern Factor Analysis. Chicago: Univ. of Chicago Press.

IGLEHART, A. (1979) Married Women and Work. Lexington, MA: D. C. Heath.

LOPATA, H. (1971) Occupation: Housewife. New York: Oxford Univ. Press.

MASON, K., J. CZAJKA, and S. ARBER (1976) "Change in U.S. women's sex-role attitudes, 1964-1974." Amer. Soc. Rev, 41, 4: 573-596.

MOLM, L. (1978) "Sex role attitudes and the employment of married women: the direction of causality." Soc. Q. 19: 522-533.

NYE, F. and L. HOFFMAN [eds.] (1963) The Employed Mother in America. Skokie, IL: Rand McNally.

PARELIUS, A. (1975) "Change and stability in college women's orientations toward education, family, and work." Social Problems 22, 3: 420-432.

RUNCIMAN, W. (1966) Relative Deprivation and Social Justice: A Study of Attitudes to Social Inequality in Twentieth-Century England. Berkeley: Univ. of California Press.

SMITH, R. [ed.] (1979) The Subtle Revolution: Women at Work. Washington, DC: The Urban Institute.

THORNTON, A. and D. FREEDMAN (1979) "Changes in the sex role attitudes of women, 1962-1977: evidence from a panel study." Amer. Soc. Rev. 44, 5: 831-842.

VEROFF, J., E. DOUVAN, and R. KULKA (1981) The Inner American: A Self-Portrait from 1957 to 1976. New York: Basic Books.

WRIGHT, J. (1978) "Are working women really more satisfied? evidence from several national surveys." J. of Marriage and the Family 40, 2: 301-313. 
ALOEN TOWNSEND is a Ph.D. candidate in social psychology at the University of Michigan, Ann Arbor. Her current research interests include social identity and intergroup relations, and causal attributions for barriers to women's labor force participation.

PATRICIA GURIN is Professor of Psychology and Faculty Associate at the Institute for Social Research, University of Michigan, Ann Arbor. Her current research interests include the role of expectancies in labor market behavior of women and minorities, and social identity and group consciousness in political behavior. 